\title{
Three dimensional simulation of tide and tidal current characteristics in the East China Sea
}

\author{
Xianwen BAO*, Guoping GAO, Ju YAN \\ College of Marine Environment, Ocean University of Qingdao, Qingdao, 266003, PR China
}

Received 21 February 2000; revised 24 October 2000; accepted 25 October 2000

\begin{abstract}
With the fine horizontal $\left(5^{\prime} \times 5^{\prime}\right)$ and vertical $(15$ levels $)$ grids, a three-dimensional model, imbedded a closure turbulence sub-model, was used to calculate the barotropic tides and tidal currents in the Bohai Sea, Yellow Sea, and East China Sea. The computational results are in good agreement with the observed M2, S2, K1 and O1 tides in the domain. Comparison with fifty tide gauges showed that the averaged absolute differences between the simulated and observed amplitudes are only $3.95,2.96,2.5$ and $1.78 \mathrm{~cm}$ for the M2, S2, K1 and O1 tidal waves, respectively. The averaged phase-lag differences of the four tides are $6.88,6.96,5.96$ and $6.16^{\circ}$. The model reproduces well the tidal charts and this characteristic is discussed in detail. Comparison with 13 current stations, gave averaged absolute deviations between the calculated and observed harmonic constant of the eastern and northern tidal current of $[6.53,20.4,7.55$, 24.9]; [3.24, 24.2, 2.89, 22.8]; [2.98, 22.4, 3.6, 25.9]; [2.39, 35.8, $2.01 \mathrm{~cm} \mathrm{~s}^{-1}, 22.6^{\circ}$ ] for $\mathrm{M} 2, \mathrm{~S} 2, \mathrm{~K} 1$ and $\mathrm{O} 1$, respectively. The calculated structures of the tidal current ellipse in the vertical are in fair agreement with the observations. The surface distributions of the tidal current ellipse in the four tidal systems and the maximum current distributions are discussed in detail. (C) 2001 Ifremer/CNRS/IRD/Éditions scientifiques et médicales Elsevier SAS
\end{abstract}

Résumé - Simulations en trois dimensions des caractéristiques des marées et des courants induits en mer de Chine. Un modèle tridimensionnel de haute résolution selon l'horizontale $\left(5^{\prime} \times 5^{\prime}\right)$ selon la verticale (quinze niveaux) incluant un modèle de fermeture de turbulence sous maille a été mis en oeuvre pour calculer les marées barotropes et les courants induits dans la mer de Bohai, la mer Jaune et la mer de Chine. Les résultats sont en accord avec les composantes M2, S2, K1 et O1 pour les sites considérés. La comparaison avec les mesures de cinquante marégraphes montre que les écarts sur les amplitudes moyennes sont seulement respectivement de 3,$95 ; 2,96 ; 2,5$ et $1,78 \mathrm{~cm}$ pour les composantes M2, S2, K1 et O1. Les déphasages moyens pour ces quatre composantes sont de 6,$88 ; 6,96 ; 5,96$ et $6,16^{\circ}$. Les performances du modèle pour reproduire les cartes de marées sont discutées. Les comparaisons des mesures de courants de treize stations donnent des écarts sur les composantes harmoniques moyennes des courants de marée vers l'est et le nord respectivement de : $[6,53 ; 20,4 ; 7,55 ; 24,9] ;[3,24 ; 24,2 ; 2,89 ; 22,8] ;[2,98 ; 22,4 ; 3,6 ; 25,9] ;[2,39 ; 35,8$; $2,01 \mathrm{~cm} \mathrm{~s}^{-1} ; 22,6^{\circ}$ ] pour M2, S2, K1 et O1. Les structures calculées du courant orbital vertical sont en bon accord avec l'observation. La distribution des courants horizontaux en surface pour les quatre composantes de la marée sont discutées en détail. () 2001 Ifremer/CNRS/IRD/Éditions scientifiques et médicales Elsevier SAS

\section{D model / tide / East China Sea}

modèle 3D / marée et courants de marée / mer de Chine

* Correspondence and reprints.

E-mail address: xwbao@public.qd.sd.cn (X. BAO). 


\section{INTRODUCTION}

The seas of East China are among of the world's major shallow water areas, and topography has a major effect in modifying deep-sea tides. As one of the most important physical processes in the East China Sea and the Yellow Sea (EYS), the tide and tidal currents have been investigated by field observations (Ogura, 1933; Nishida, 1980; Larsen et al., 1985; Fang, 1986) and numerical models (An, 1977; Shen, 1980; Choi, 1984, 1989; Ding, 1984; Zhao et al., 1994; Ye and Mei, 1995; Guo and Yanagi, 1998; Kang et al., 1998; Wan et al., 1998; Lee and Jung, 1999; Wang et al., 1999; Lefevre et al., 2000). General information about the tidal dynamics in the region is now available. Since few observed tidal current data were obtained, and most numerical models are horizontally two-dimensional, little is known about the threedimensional structure of tidal current in the region and this must be investigated or simulated by models.

Among the numerical models of the tidal and tidal currents in the EYS, some are based on the boundary value method in which the tides were calculated in the domain by the harmonic constants along the coast (Shen, 1980; Ding, 1984). Other models are based on the initial value method in which the tides were reproduced from the harmonic constants on the open boundary (An, 1977; Choi, 1984, 1989; Zhao et al., 1994; Ye and Mei, 1995; Guo and Yanagi, 1998; Kang et al., 1998; Wan et al., 1998; Lee and Jung, 1999; Wang et al., 1999). The latter method is more logical and has recently become popular.

Table I, which summarizes the main characteristics of the tidal models in the EYS based on the initial value method, shows that most tide models are horizontally twodimensional. Most models, except Choi (1984, 1989), include a nonlinear advective term. The horizontal eddy viscosity has little influence on the tide because it acts as a scale-selective filter, damping the shorter waves more heavily than the long waves (Davies et al., 1977). Including it or not in the tide model should not be a serious problem. The effect of the tide-generated force of the M2 tide in this region is said to be less than 3\% (An, 1977) and is usually ignored. In three-dimensional tidal models for the EYS, the vertical eddy viscosity was to set a constant or a simple relation to the depth and velocity. The vertical eddy viscosity represents the interior friction of tidal current and may have a large effect on the calculated tidal current near the sea bottom (Davies et al., 1997). Wan et al. (1998) succeeded in representing the M2 tidal wave in the region by Princeton ocean model (POM). An important reason is that the POM contains a second moment turbulence closure sub-model to provide vertical eddy viscosity. In order to accurately determine the characteristics and structure of the tidal currents in the EYS, it is necessary to use a three-dimensional model, imbedded turbulence closure sub-model, with sufficiently fine horizontal and vertical resolution to simulate the tidal current in the EYS.

Although all of the models summarized in table I have been used to simulate the EYS tidal wave, a numerical simulation of the four main tides with a model including all dynamic items with fine grids would facilitate the characterization of the semi-diurnal and diurnal tides and the tidal current. The equations including all dynamic

Table I. Summary of the tidal models in the East China Sea and the Yellow Sea.

\begin{tabular}{|c|c|c|c|c|c|}
\hline Authors & Tide & Dimension & $\mathrm{ADV}$ & HEV & VEV \\
\hline An (1977) & M2 & $2 \mathrm{D}$ & Yes & Yes & \\
\hline Choi (1984) & Four & $2 \mathrm{D}$ & Yes & No & \\
\hline Yanagi and Inoue (1994) & Four & $2 \mathrm{D}$ & Yes & Yes & \\
\hline Zhao et al.(1994) & Four & $2 \mathrm{D}$ & Yes & Yes & \\
\hline Ye and Mei (1995) & Four & $2 \mathrm{D}$ & Yes & No & \\
\hline Kang et al (1998) & M2 & $2 \mathrm{D}$ & Yes & Yes & \\
\hline Choi (1984) & M2 & $3 \mathrm{D}$ & No & No & Const \\
\hline Choi (1989) & M2 & $3 \mathrm{D}$ & No & No & Const \\
\hline Guo and Yanagi (1998) & Four & $3 \mathrm{D}$ & Yes & Yes & Simple \\
\hline Wan et al. (1998) & $\mathrm{M} 2, \mathrm{~m} 1$ & $3 \mathrm{D}$ & Yes & Yes & Close \\
\hline Wang et al.(1999) & M2 & $3 \mathrm{D}$ & Yes & Yes & Simple \\
\hline Lee and Jung (1999) & Five & $3 \mathrm{D}$ & Yes & Yes & Close \\
\hline
\end{tabular}

Four means M2, S2, K1, O1 tides; ADV, advective terms; HEV and VEV, horizontal and vertical eddy viscosity; 2D and 3D, two and three-dimensional model respectively. 
items, boundary conditions and the turbulence closure model are described in section 2. The operation-split method is used for discrete equations, so the time integration of the momentum equations in a time step is partitioned into three sequential substeps. The finite difference formulation and scheme are introduced in section 3. The model application, comparison with observed data and discussion of the results are in section 4 .

\section{NUMERICAL MODEL EQUATION}

\subsection{Dynamic equation}

Assuming constant density, the tides and tidal currents are controlled by the following equations in a sigma coordinate system, in which the $\mathrm{X}$-axis is eastward, Y-axis northward, and $\sigma$ upward form the surface $(\sigma=0)$. The derivation of the sigma coordinate equation was given in detail in Blumberg and Mellor (1987).

$$
\begin{gathered}
\frac{\partial \eta}{\partial t}+\frac{\partial u D}{\partial x}+\frac{\partial v D}{\partial y}+\frac{\partial \omega}{\partial \sigma}=0 \\
\frac{\partial u D}{\partial t}+\frac{\partial u^{2} D}{\partial x}+\frac{\partial u v D}{\partial y}+\frac{\partial u \omega}{\partial \sigma}-f v D+g D \frac{\partial \eta}{\partial t} \\
=\frac{\partial}{\partial \sigma}\left(\frac{K_{M}}{D} \frac{\partial u}{\partial \sigma}\right)+\frac{\partial}{\partial x}\left(2 A_{M} D \frac{\partial u}{\partial x}\right)+\frac{\partial}{\partial y}\left[A_{M} D\left(\frac{\partial u}{\partial y}+\frac{\partial v}{\partial x}\right)\right] \\
\frac{\partial v D}{\partial t}+\frac{\partial u v D}{\partial x}+\frac{\partial \nu^{2} D}{\partial y}+\frac{\partial r w}{\partial \omega} f u D+g D \frac{\partial \eta}{\partial y} \\
=\frac{\partial}{\partial \sigma}\left(\frac{K_{M}}{D} \frac{\partial v}{\partial \sigma}\right)+\frac{\partial}{\partial y}\left(2 A_{M} D \frac{\partial v}{\partial y}\right)+\frac{\partial}{\partial x}\left[A_{M} D\left(\frac{\partial u}{\partial y}+\frac{\partial v}{\partial x}\right)\right]
\end{gathered}
$$

where $u, v$ are eastward and northward velocities respectively; $K_{M}$, the vertical eddy diffusivity of turbulent momentum mixing; $A_{M}$, horizontal diffusivity; $D=H+\eta$, where $H(x, y)$ is the bottom topography and $\eta(x, y, t)$ is the surface elevation. $\sigma$ ranges from surface $(\sigma=0)$ at $z=\eta$ to $\sigma=-1$ at $z=-H$. $\omega$ is the transformed velocity which is normal to sigma surface.

$\omega=w-u\left(\sigma \frac{\partial D}{\partial x}+\frac{\partial \eta}{\partial x}\right)-v\left(\sigma \frac{\partial D}{\partial y}+\frac{\partial \eta}{\partial y}\right)-\left(\sigma \frac{\partial D}{\partial t}+\frac{\partial \eta}{\partial t}\right)$

\subsection{Turbulence closure}

The turbulence closure sub-model, advanced by Mellor and Yamada (1982) is used, together with an equation for the turbulence macroscale. The closure model is described in detail in Blumberg and Mellor (1987). The closure model equation is as follows:

$$
\begin{gathered}
\frac{\partial q^{2} D}{\partial t}+\frac{\partial u q^{2} D}{\partial x}+\frac{\partial v q^{2} D}{\partial y}+\frac{\partial \omega q^{2} D}{\partial \sigma} \\
=\frac{\partial}{\partial \sigma}\left(\frac{K_{q}}{D} \frac{\partial q^{2}}{\partial \sigma}\right)+\frac{2 K_{M}}{D} \\
{\left[\left(\frac{\partial u}{\partial \sigma}\right)^{2}+\left(\frac{\partial v}{\partial \sigma}\right)^{2}\right]-\frac{2 D q^{2}}{A_{1}}} \\
+\frac{\partial}{\partial x}\left(D A_{H} \frac{\partial q^{2}}{\partial x}\right)+\frac{\partial}{\partial y}\left(D A_{H} \frac{\partial q^{2}}{\partial y}\right) \\
\frac{\partial q^{2} l D}{\partial t}+\frac{\partial u q^{2} l D}{\partial x}+\frac{\partial v q^{2} l D}{\partial y}+\frac{\partial \omega q^{2} D}{\partial \sigma} \\
=\frac{\partial}{\partial \sigma}\left(\frac{K_{q}}{D} \frac{\partial q^{2} l}{\partial \sigma}\right)+\frac{E_{1} l K_{M}}{D} \\
{\left[\left(\frac{\partial u}{\partial \sigma}\right)^{2}+\left(\frac{\partial v}{\partial \sigma}\right)^{2}\right]-\frac{D q^{3}}{B_{1}} \bar{W}+\frac{\partial}{\partial x}\left(D A_{H} \frac{\partial q^{2} l}{\partial x}\right)} \\
+\frac{\partial}{\partial y}\left(D A_{H} \frac{\partial q^{2} l}{\partial y}\right)
\end{gathered}
$$

where $\frac{q^{2}}{2}$ is turbulence kinetic energy; $l$, turbulence macroscale $-\rho$, water density $-\rho=1 \times 10^{3} \mathrm{Kg} / \mathrm{m}^{3}-\bar{W}$, wall proximity function, was defined as:

$$
\begin{gathered}
\bar{W}=1+E_{2}\left(\frac{l}{k L}\right)^{2} \\
\text { and where } \\
(L)^{-1}=(\eta-z)^{-1}+(H+z)^{-1}
\end{gathered}
$$

While details of the closure model are rather involved, it is possible to reduce the prescription of the mixing coefficients $K_{M}$ and $K_{q}$ to the following expressions:

$$
\begin{aligned}
K_{M} & =l q S_{M} \\
K_{q} & =l q S_{q}
\end{aligned}
$$

$S_{M}$ and $S_{q}$ are stability functions obtained as follows:

$$
\begin{gathered}
G_{M}=\frac{l^{2}}{q^{2} D}\left[\left(\frac{\partial u}{\partial \sigma}\right)^{2}+\left(\frac{\partial v}{\partial \sigma}\right)^{2}\right]^{1 / 2} \\
S_{M}\left(1+6 A_{1}^{2} G_{M}-9 A_{1} A_{2} G_{H}\right)=A_{1}\left(1-3 C_{1}\right) \\
S_{q}=0.2
\end{gathered}
$$

In the equations (5) to (13) $-A_{1}, A_{2}, C_{1}, E_{1}, E_{2}$ are empirical constants assigned the following values:

$$
\left(A_{1}, A_{2}, E_{1}, E_{2}, C_{1}\right)=(0.92,0.74,1.8,1.33,0.08)
$$




\subsection{Boundary conditions}

The dynamic boundary conditions at the free surface $(\sigma=0)$ are:

$$
\rho \frac{K_{M}}{D}\left(\frac{\partial u}{\partial \sigma}, \frac{\partial v}{\partial \sigma}\right)=\left(\tau_{a x}, \tau_{a y}\right)
$$

For the tidal simulation, $\bar{\tau}_{a}=0$.

At the bottom $(\sigma=-1)$,

$$
\frac{K_{M}}{D}\left(\frac{\partial u}{\partial \sigma}, \frac{\partial v}{\partial \sigma}\right)=C_{b}\left(u^{2}+v^{2}\right)^{1 / 2}(u, v)
$$

The kinetic boundary conditions at the surface and bottom,

$$
\omega(0)=\omega(-1)=0
$$

At lateral boundary,

$$
V_{\bar{n}}(x, y, \sigma, t)=0
$$

where $\bar{n}$ is normal direction of lateral boundary.

On the open boundary, the elevation are obtained from the tidal constituents:

$$
\eta(t)=\sum f_{i} A_{i} \cos \left(\omega_{i} t-\theta_{i}+V_{0 i}+U_{i}\right)
$$

where $A_{i}$ and $\theta_{i}$ are harmonic constants for the amplitude and phase-lag respectively, $\omega_{i}$ is the angular speed of the tidal constituents, $f_{i}$ the nodal factor, $U_{i}$ the nodal angle, $V_{0 i}$ the initial phase angle.

\subsection{Finite difference formulation}

The governing equations form a set of simultaneous partial differential equations that cannot be solved using known analytic methods. The equations require numerical computational methods using discretized equations in temporal and spatial. In anticipation of constructing the finite differencing scheme, the governing equations have been cast into their flux forms. This is to ensure that certain integral constraints are maintained by the differencing.

The momentum equations account for the fluid advection, horizontal and vertical diffusions, Coriolis force, and pressure variation. The characteristic temporal and spatial scales associated with these hydraulic phenomena span several orders of magnitude. Thus, each mathematical term in the momentum equations carries a certain amount of physical and numerical significance in a hydrodynamic model. For instance, the pressure gradient terms are principally responsible for the general movement of water. The vertical diffusion terms are key elements in a 3D model. The non-linearity of the advection terms easily causes numerical instability. Conversely, the horizontal diffusion terms have a smoothing effect that creates a more stable numerical environment. It is better to treat these terms with suitable numerical methods according to their particular physical and numerical nature.

In this model, the time integration of the momentum equations in a time step is partitioned into three sequential substeps. The first substep, the system constituting the advection, Coriolis force terms and horizontal diffusion terms is solved for the velocity. In general, numerical instability in hydrodynamic computations is mainly caused by the incorrect approximation of the advection terms; to improve the numerical stability, the advection terms in this system are discretized at an integer time step. The equations in this substep are given as:

$$
\begin{array}{r}
\frac{D^{n} u^{n+1 / 3}-(D u)^{n}}{\Delta t}+\frac{\partial u^{2} D}{\partial x}+\frac{\partial u v D}{\partial y}+\frac{\partial u \omega}{\partial \sigma}-f v D \\
=\frac{\partial}{\partial x}\left[2 A_{M} D \frac{\partial u}{\partial x}\right]+\frac{\partial}{\partial y}\left[2 A_{M} D\left(\frac{\partial u}{\partial y}+\frac{\partial v}{\partial x}\right)\right] \\
\frac{D^{n} v^{n+1 / 3}-(D v)^{n}}{\Delta t}+\frac{\partial u v D}{\partial x}+\frac{\partial v^{2} D}{\partial y}+\frac{\partial v \omega}{\partial \sigma}+f u D \\
=\frac{\partial}{\partial y}\left[2 A_{M} D \frac{\partial v}{\partial y}\right]+\frac{\partial}{\partial x}\left[A_{M} D\left(\frac{\partial u}{\partial y}+\frac{\partial v}{\partial x}\right)\right]
\end{array}
$$

The surface shear stresses and the bottom friction are essentially associated with the diffusion in a 3D model. In order to solve the vertical velocity profile, only the vertical diffusion terms are considered in the second substep, as follows:

$$
\begin{aligned}
& \frac{D^{n} u^{n+2 / 3}-D^{n} u^{n+1 / 3}}{\Delta t}=\frac{\partial}{\partial \sigma}\left(\frac{K_{m}}{D} \frac{\partial u}{\partial \sigma}\right) \\
& \frac{D^{n} v^{n+2 / 3}-D^{n} v^{n+1 / 3}}{\Delta t}=\frac{\partial}{\partial \sigma}\left(\frac{K_{m}}{D} \frac{\partial v}{\partial \sigma}\right)
\end{aligned}
$$

Shallow water flows with free surfaces are principally driven by pressure gradients. Therefore, the pressure 
gradients are used to determine the velocity in the last substep, as shown below:

$$
\begin{aligned}
& \frac{(D u)^{n+1}-D^{n} u^{n+2 / 3}}{\Delta t}=-g D \frac{\partial \eta}{\partial x} \\
& \frac{(D v)^{n+1}-D^{n} v^{n+2 / 3}}{\Delta t}=-g D \frac{\partial \eta}{\partial y}
\end{aligned}
$$

To derive the finite difference equations, the following sum and difference operations are defined:

${\overline{F(x, y, \sigma, t)^{x}}}^{x}=\frac{F\left(x+\frac{\Delta x}{2}, y, \sigma, t\right)+F\left(x-\frac{\Delta x}{2}, y, \sigma, t\right)}{2}$

$\delta_{x} F(x, y, \sigma, t)=\frac{F\left(x+\frac{\Delta x}{2}, y, \sigma, t\right)-F\left(x-\frac{\Delta x}{2}, y, \sigma, t\right)}{\Delta x}$

$\delta_{x} \overline{F(x, y, \sigma, t)}=\frac{F(x+\Delta x, y, \sigma, t)-F(x-\Delta x, y, \sigma, t)}{2 \Delta x}$

$\overline{F(x, y, \sigma, t)}{ }^{x y}=\overline{\overline{F(x, y, \sigma, t)}}{ }^{x}=\overline{\overline{F(x, y, \sigma, t)^{y}}} x$

The bar and delta $(\delta)$ operators form a commutative and distributive algebra. A variable $F(x, y, \sigma, t)$ can now be written as $F_{i, j, k}^{n}$. The variables are staggered on the computational " $C$ " grid. The $\Delta x$ are the constant horizontal grid spacing respectively, and $\Delta \sigma$ is the vertical increment which varies in thickness to accommodate more resolution near the bottom.

The finite difference equations (19), (21), (23), (20), (22) and (24) are written as:

$$
\begin{aligned}
& \frac{D^{n} u^{n+1 / 3}-(D u)^{n}}{\Delta t}+\delta_{x}\left(\overline{\bar{D}^{x} u^{x}} \bar{u}^{x}\right)^{n}+\delta_{y}\left(\overline{\bar{D}^{x} u^{y}} \bar{v}^{x}\right)^{n} \\
& +\delta_{\sigma}\left(\bar{\omega}^{x} \bar{u}^{\sigma}\right)^{n}-\overline{f \bar{v}^{y} D^{x^{n}}} \\
& =\delta_{x}\left[2{\overline{A_{M} D}}^{x} \delta_{x}(u)\right]^{n}+\delta_{y}\left\{{\overline{A_{M} D^{y}}}^{y}\left[\delta_{y}(u)+\delta_{x}(v)\right]\right\}^{n}
\end{aligned}
$$

$$
\begin{aligned}
& \frac{D^{n} u^{n+2 / 3}-D^{n} u^{n+1 / 3}}{\Delta t}=\delta_{\sigma}\left[\frac{{\overline{K_{M}}}^{x}}{\bar{D}^{x}} \delta_{\sigma}(u)^{n+2 / 3}\right] \\
& \frac{(D u)^{n+1}-D^{n} u^{n+2 / 3}}{\Delta t}=-g \bar{D}^{x} \delta_{x}(\eta)^{n+1} \\
& \frac{D^{n} v^{n+1 / 3}-(D v)^{n}}{\Delta t}+\delta_{x}\left(\overline{\bar{D}^{x} u^{y}} \bar{v}^{x}\right)^{n}+\delta_{y}\left(\overline{\bar{D}^{y} v^{y}} \bar{v}^{y}\right)^{n} \\
& +\delta_{\sigma}\left(\bar{\omega}^{y} \bar{v}^{\sigma}\right)^{n}+{\overline{f u^{x}}}^{y^{n}} \\
& \left.=\delta_{x}\left[2{\overline{A_{M} D}}^{y} \delta_{y}(v)\right]^{n}+\delta_{x}\left\{{\overline{A_{M} D^{x}}}^{x} \delta_{y}(u)+\delta_{x}(v)\right]\right\}^{n} \\
& \frac{D^{n} v^{n+2 / 3}-D^{n} v^{n+1 / 3}}{\Delta t}=\delta_{\sigma}\left[\frac{\bar{K}_{M}^{y}}{\bar{D}^{y}} \delta_{\sigma}(v)^{n+2 / 3}\right] \\
& \frac{(D v)^{n+1}-D^{n} v^{n+2 / 3}}{\Delta t}=-g \bar{D}^{y} \delta_{y}(\eta)^{n+1}
\end{aligned}
$$

The finite difference equations of the continuity equation (1) and turbulence closure equations (5) and (6) are written as

$$
\begin{aligned}
& \frac{\eta^{n+1}-\eta^{n}}{\Delta t}+\delta_{x}\left(\bar{D}^{x} u\right)^{n+1}+\delta_{y}\left(\bar{D}^{y} v\right)^{n+1}+\delta_{\sigma}(\omega)^{n+1}=0 \\
& \frac{\left(q^{2} D\right)^{n+1}-\left(q^{2} D\right)^{n}}{\Delta t}+\delta_{x}\left(\bar{u}^{\sigma} \bar{D}^{x} \bar{q}^{2 x}\right)^{n}+\delta_{y}\left(\bar{v}^{\sigma} \bar{D}^{y} \bar{q}^{2 x}\right)^{n} \\
& =\delta_{\sigma}\left(\frac{K_{q}}{D} \delta_{\sigma} q^{2}\right)^{n+1}+\frac{2 K_{M}}{D}\left[\left(\delta_{\sigma} \bar{u}^{x}\right)^{2}+\left(\delta_{\sigma} \bar{v}^{y}\right)^{2}\right]^{n} \\
& -\frac{2 D q^{3}}{A_{1}}+\delta_{x}\left(\bar{D}^{x}{\overline{A_{H}}}^{\sigma} \delta_{x} q^{2}\right)^{n}+\delta_{y}\left(\bar{D}^{y}{\overline{A_{H}}}^{\sigma}\right)^{n} \\
& \frac{\left(q^{2} l D\right)^{n+1}-\left(q^{2} l D\right)^{n}}{\Delta t}+\delta_{x}\left(\bar{u}^{\sigma} \bar{D}^{x} \overline{q^{2} l^{x}}\right)^{n} \\
& +\delta_{y}\left(\bar{v}^{\sigma} \bar{D}^{y} \overline{q^{2} l^{y}}\right)^{n}+\delta_{\sigma}\left(\bar{\omega}^{\sigma} \overline{q^{2} l^{\sigma}}\right)^{n} \\
& =\delta_{\sigma}\left(\frac{K_{q}}{D} \delta_{\sigma} q^{2} l\right)^{n+1}+l E_{1} \frac{K_{M}}{D}\left[\left(\delta_{\sigma} \bar{u}^{x}\right)^{2}+\left(\delta_{\sigma} \bar{v}^{y}\right)^{2}\right]^{n} \\
& -\frac{D q^{3}}{B_{1}}\left\{1+E_{2}\left[\frac{l}{k D}\left(\frac{1}{\sigma}+\frac{1}{1+\sigma}\right)\right]^{2}\right\} \\
& +\delta_{x}\left(\bar{D}^{x} \overline{A_{H}}{ }^{\sigma} \delta_{x} q^{2} l\right)+\delta_{y}\left(\bar{D}^{x}{\overline{A_{H}}}^{\sigma} \delta_{y} q^{2} l\right)^{n}
\end{aligned}
$$

We can obtain the solution of $u^{n+1 / 3}$ and $v^{n+1 / 3}$ by resolving explicity the equations (29) and (32). Equations (30) and (33) are used to update $u^{n+2 / 3}$ and $v^{n+2 / 3}$ by the recusion reduction for a tridiagonal linear system, respec- 
tively. Combining the equations (31) and (34) with (35), the elevation $\eta^{n+1}$ is obtained in a five diagonal linear system by use of the semi-implicit method (Casulli 1990). After the elevation $\eta^{n+1}$ are obtained, the velocity $u^{n+1}$, $v^{n+1}$ and $\omega^{n+1}$ are updated in equations (31), (34) and (35). Finally, the equation (36) and (37) in the turbulence model can be explicitly resolved to provide the mixing coefficients $K_{M}^{n+1}$ and $K_{q}^{n+1}$.

\section{MODEL APPLICATION AND RESULTS}

\subsection{Model parameters and verification}

The topography of the model's domain is shown in figure 1. The fifteen vertical levels are taken inside the water column. The calculations were made in grids with $161 \times 203$ nodes in each level and a grid space of $5^{\prime} \times 5^{\prime}$ on latitude and longitude. The zero initial conditions for elevation and current were used. The time step is $300 \mathrm{~s}$ and bed drag coefficient is calculated by the empirical formulation as following:

$$
C_{b}=\min \left\{\frac{0.016}{[1+\log (h / 2)]^{2}}, 0.0015\right\}
$$

Boundary conditions for the tidal model are no flow normal to the coast and specified elevations along the open boundaries. The open boundaries consist of three sections: the Taiwan Strait, a section along the Ryukya Islands, and the Korea Strait. The harmonic constants on the open boundaries were determined using available tidal data, existing model results (Fang, 1986) and empirical charts (Nishida, 1980), and an interpolation procedure.

After $240 \mathrm{~h}$, the tidal waves had already stabilized. The processing of the elevation and current fields were carried out in two stages. The first, the simulated data of elevation and current were recorded in each grid after $240 \mathrm{~h}$. Then, these time series were used for harmonic analysis, and the harmonic constants of elevation and current were calculated.

The model was verified by comparison with observations at the fifty tidal gauges. The positions of the tidal gauges and the corresponding station number are plotted in figure 1. The harmonic constants of the four major tides were selected to verify the model results. Due to the limited

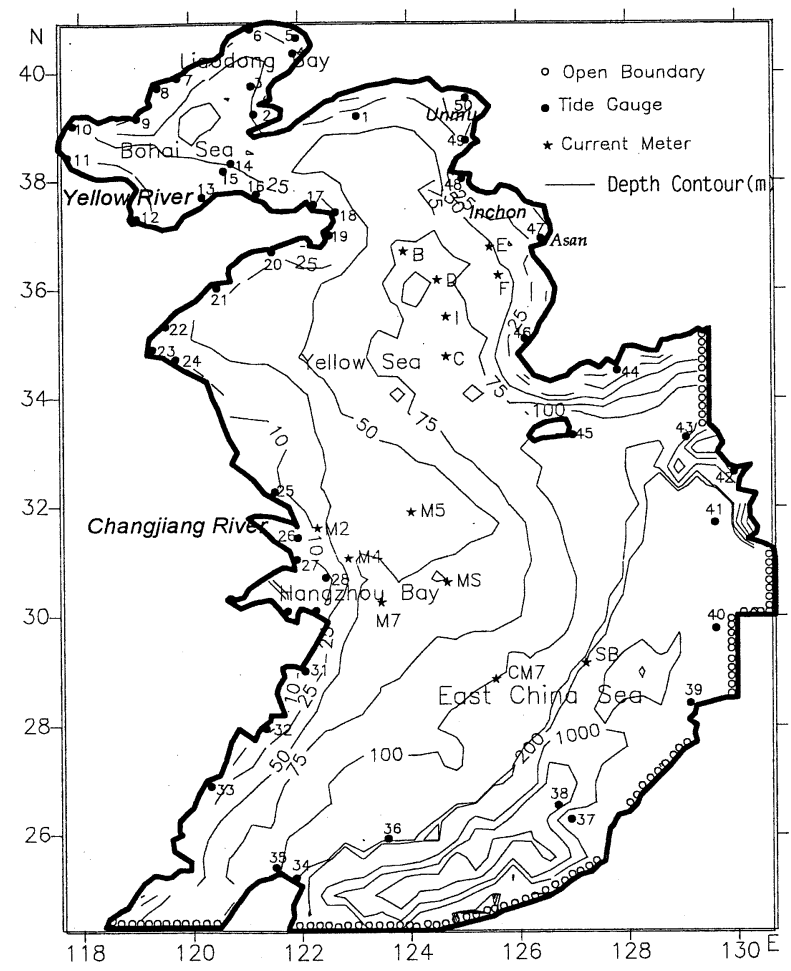

Figure 1. Topography of the East China Sea, the Yellow Sea and the Bohai Sea. The positions of the open boundary, tidal gauges and the observed tidal current data are shown by open circles, closed circles, and stars, respectively.

horizontal resolution, the positions of the corresponding grids of tidal gauges were different from their actual positions. The average value of the four grids close to gauges was replaced by the model's value in the gauges. Comparisons of the calculated harmonic constants of tidal elevation with the observations at fifty tidal gauge stations are shown in table II. An averaged absolute difference between the simulated and observed amplitudes is only $3.95,2.96,2.5$ and $1.78 \mathrm{~cm}$ for the M2, S2, $\mathrm{K} 1$ and $\mathrm{O} 1$ tidal waves, respectively. The averaged difference of phase-lags of the four tides is $6.88,6.96$, 5.96 and $6.16^{\circ}$, respectively. The differences are smaller than those in Zhao et al. (1994), Ye and Mei (1995) and Wang et al. (1999). The model's elevations are in good agreement with the observations as well, except for a few stations that are located in the mouth of Changjiang River and on the coast in the Hangzhou Bay. The errors made in the above region are attributed to the complex topography, as a vast sand bar and drying banks exist and the model did not resolve this local feature correctly. 
That the model's results are in good agreement with tidal gauges clearly shows that the model can simulate the EYS tides very well.

Tidal model currents were evaluated by comparison with observations at 13 current mooring stations shown in figure 1. The comparisons between the observed and calculated tidal currents of M2, S2, K1, and $\mathrm{O} 1$ are listed in table III. The observed tidal current data are from Larsen et al. (1985) and Choi (1984, 1989). A summary of this data was given in Guo and Yanagi (1998). The positions of the current observations are located from the shelf-break of the East China Sea to the north Yellow Sea. Many of the current meter records are shorter than the 30 days generally required for tidal observation, so a leastsquare algorithm was used to determine the tidal current harmonics (Larsen et al., 1985). Most of the current amplitude and phase lag errors are less than $10 \mathrm{~cm} \mathrm{~s}^{-1}$ and $30^{\circ}$, respectively. The larger errors of four tidal currents occurred at the same stations or same level (such as E station and $5 \mathrm{~m}$ level in M5 station). The comparison of the results in table III indicates that the calculated current fields are in fair agreement with those observed.

Comparisons of model-generated current ellipses with those observed at four stations were shown in figure 2. Here M2 is the largest constituent in the EYS. Figure $2 a$ shows the M2, S2, K1 and O1 ellipses versus depth at M4 station. The current ellipses in M4 are slightly changed in the vertical. The ellipses of M2 and S2 display a better agreement with observation than those of the $\mathrm{K} 1$ and $\mathrm{O} 1$ tides.

Figure $2 b$ shows the current ellipses at MS mooring station. The model results for M2 and K1 are satisfactory, but the modeled ellipses of $\mathrm{S} 2$ are smaller than those observed, and the major axis direction of $\mathrm{O} 1$ declines to that from the observation by about $50^{\circ}$.

Figure $2 c$ shows the tidal ellipse at M7 station. The result of comparison is similar to M4 station. The simulation of semidiurnal currents is better than that of diurnal currents. The calculated magnitudes of the $\mathrm{K} 1$ and $\mathrm{O} 1$ currents are larger than observations.

Figure $2 d$ shows the tidal ellipses at M5 station. The calculated currents at 25 and $45 \mathrm{~m}$ are in good agreement with observations. The data of a diurnal current at $5 \mathrm{~m}$ may be incorrect, because they are too large to display the tidal current characteristics that are evident in many observations.
From figure 2, we conclude that the model simulates the semidiurnal current better than the diurnal current. Comparing the errors on table II with table III, the resolution in tidal elevation simulation is better than that for tidal current simulation using the model. An important reason could be that the water stratification and baroclinic processes were not considered in our model.

\subsection{Tidal elevation characteristics}

The calculated co-amplitude and co-phase lag lines of four tidal constituents are shown in figure 3. The pattern of the M2 tidal wave system is similar to S2. The characteristics of co-tidal charts is that there exist four amphidromic points in the domain. Two are located in the Bohai Sea and the others in the Yellow Sea. According to previous work, the two in the Yellow Sea are stable and the others in the Bohai Sea are unstable. The existence of the amphidromic point in the mouth of the Yellow River has been suggested (Ogura, 1933; Fang,1986; Guo and Yanagi,1998; Bao et al., 2000). The difference of its location was attributed to the change of the coastline of the Yellow River Delta (Fang, 1986). The amphidromic point in the Liaodong Bay was not present in some models (Choi, 1984; 1989; Yanagi and Inoue, 1994). Whether it was present or not will determine how to choose the bed drag coefficient in the model (Guo and Yanagi, 1998). In fact, the choice of the bed drag coefficient may be the most important problem in the tidal model. The bottom friction term has been expressed in quadratic friction form and the bed drag coefficient is a constant in most tidal models in the EYS. However, the model domain covers the shallow part (less than $100 \mathrm{~m}$ ) of the Yellow Sea and the deep part (up to $3000 \mathrm{~m}$ ) in the Okinawa Trough. This implied that non-uniformity of bottom friction might be required (Kang et al., 1998). Comparison of observations mentioned above indicated that the empirical depth-dependant form (equation 38) of the bed drag coefficient is good to use in our model. The value calculated by (equation 38 ) is close at the threshold value, 0.0015 , which had been given by Lefevre et al. (2000). By the test in our simulation, the amphidromic points in the Bohai Sea are sensitive to the coastline and depth variations, besides the bed drag coefficient in the model. Amphidromic points in the Yellow Sea are not as sensitive as that in the Bohai Sea, but their positions are affected by the phase lag of constituent in the east open boundary. The locations given by Guo and Yanagi (1998) 
Table II. Comparison between the observed and calculated M2, S2, K1 and O1 elevation.

\begin{tabular}{|c|c|c|c|c|c|c|c|c|c|c|}
\hline \multirow[b]{2}{*}{ No. } & \multirow[b]{2}{*}{ Latitude } & \multirow[b]{2}{*}{ Longitude } & \multicolumn{2}{|l|}{ M2 } & \multicolumn{2}{|l|}{$\mathrm{S} 2$} & \multicolumn{2}{|l|}{$\mathrm{K} 1$} & \multicolumn{2}{|l|}{$\mathrm{O} 1$} \\
\hline & & & $\Delta H(\mathrm{~cm})$ & $\Delta g\left(^{\circ}\right)$ & $\Delta H(\mathrm{~cm})$ & $\Delta g\left(^{\circ}\right)$ & $\Delta H(\mathrm{~cm})$ & $\Delta g\left({ }^{\circ}\right)$ & $\Delta H(\mathrm{~cm})$ & $\Delta g\left({ }^{\circ}\right)$ \\
\hline 1 & 3904 & 12309 & -2 & 8 & -1 & 5 & 4 & 3 & 1 & 7 \\
\hline 2 & 3856 & 12140 & 2 & -5 & 2 & -2 & 6 & 3 & 3 & 5 \\
\hline 3 & 3939 & 12128 & 0 & 11 & 1 & 4 & -2 & -5 & -1 & -6 \\
\hline 4 & 4018 & 12206 & 3 & 12 & -2 & -9 & 0 & -4 & 2 & 4 \\
\hline 5 & 4038 & 12209 & -4 & 7 & 4 & -10 & 3 & -6 & 3 & 8 \\
\hline 6 & 4043 & 12059 & 3 & 2 & 2 & 5 & 0 & 2 & 1 & 10 \\
\hline 7 & 3955 & 11937 & 1 & -8 & -1 & 7 & -2 & -5 & 0 & 12 \\
\hline 8 & 3935 & 11917 & 0 & -9 & 1 & -5 & -1 & 3 & 1 & 6 \\
\hline 9 & 3910 & 11852 & -1 & 0 & 2 & -6 & 0 & 3 & -4 & -1 \\
\hline 10 & 3900 & 11743 & -3 & 1 & 3 & 9 & -2 & -6 & 0 & -3 \\
\hline 11 & 3837 & 11736 & 7 & 4 & 5 & 8 & -3 & -5 & -2 & 5 \\
\hline 12 & 3719 & 11859 & 5 & 8 & -2 & 1 & -4 & 4 & 0 & 6 \\
\hline 13 & 3739 & 12019 & -3 & -11 & -1 & -6 & -2 & 6 & -1 & 8 \\
\hline 14 & 3822 & 12054 & 0 & 5 & 2 & 5 & 2 & 10 & 0 & -8 \\
\hline 15 & 3810 & 12045 & 2 & 4 & 2 & 8 & 1 & 3 & 7 & -5 \\
\hline 16 & 3733 & 12123 & 9 & 7 & -3 & 11 & -4 & -11 & -3 & 7 \\
\hline 17 & 3731 & 12207 & 6 & 8 & -4 & -7 & 2 & -6 & 2 & -3 \\
\hline 18 & 3723 & 12240 & 6 & 12 & -3 & -8 & 2 & 5 & 2 & -7 \\
\hline 19 & 3653 & 12225 & -2 & 13 & 2 & 5 & -3 & 4 & 0 & -9 \\
\hline 20 & 3648 & 12129 & 3 & 9 & 1 & 12 & -3 & 7 & -4 & -13 \\
\hline 21 & 3605 & 12018 & -4 & 10 & 0 & 4 & -4 & 3 & -3 & -6 \\
\hline 22 & 3523 & 11933 & 10 & 12 & -1 & 5 & -5 & 3 & -4 & -3 \\
\hline 23 & 3445 & 11927 & 7 & 3 & 2 & 6 & -6 & 12 & -5 & -4 \\
\hline 24 & 3429 & 11947 & 5 & 14 & 5 & 8 & -5 & 7 & -4 & -1 \\
\hline 25 & 3207 & 12135 & -9 & -8 & -7 & -18 & -3 & -8 & 2 & 7 \\
\hline 26 & 3125 & 12214 & 5 & -12 & -4 & -15 & 3 & 6 & 2 & -3 \\
\hline 27 & 3107 & 12154 & -3 & -15 & -5 & -8 & -1 & -3 & 2 & 4 \\
\hline 28 & 3049 & 12237 & -1 & -2 & 3 & 3 & 0 & -9 & 1 & -10 \\
\hline 29 & 3015 & 12218 & -7 & -5 & 1 & 7 & 2 & -5 & -1 & -4 \\
\hline 30 & 2957 & 12117 & -6 & -6 & 6 & 4 & 2 & -8 & -2 & 6 \\
\hline 31 & 2913 & 12157 & 1 & -8 & 3 & -11 & -2 & 4 & -1 & 3 \\
\hline 32 & 2805 & 12117 & 3 & 9 & 2 & -5 & -3 & -7 & 2 & 5 \\
\hline 33 & 2658 & 12010 & -8 & 2 & -11 & 3 & -4 & -7 & 0 & -2 \\
\hline 34 & 2509 & 12145 & -3 & -4 & -4 & 9 & -2 & 12 & -3 & 8 \\
\hline 35 & 2511 & 12126 & -9 & 7 & -5 & 14 & -1 & 8 & -1 & 3 \\
\hline 36 & 2556 & 12341 & 2 & 5 & 1 & -10 & -2 & -1 & -2 & 5 \\
\hline 37 & 2613 & 12718 & 1 & 4 & -1 & 8 & 0 & -5 & 1 & 7 \\
\hline 38 & 2620 & 12644 & -2 & -6 & -3 & -6 & 1 & 8 & 0 & 6 \\
\hline 39 & 2827 & 12939 & 1 & -5 & -1 & -2 & 0 & 6 & 1 & 4 \\
\hline 40 & 2950 & 12951 & 2 & -5 & -2 & -6 & -1 & 9 & 2 & 5 \\
\hline 41 & 3151 & 12951 & 2 & -5 & -5 & -6 & -1 & 9 & 1 & 5 \\
\hline 42 & 3212 & 13001 & -3 & 4 & -2 & 5 & 3 & -4 & -1 & -7 \\
\hline 43 & 3259 & 12907 & -1 & 3 & 0 & 7 & -1 & -6 & 0 & -1 \\
\hline 44 & 3443 & 12803 & 7 & 7 & 8 & 4 & 4 & 5 & 2 & 8 \\
\hline 45 & 3312 & 12648 & 3 & 2 & 7 & 2 & 4 & 3 & -1 & 12 \\
\hline 46 & 3521 & 12601 & -8 & -12 & 1 & -15 & 3 & -6 & -2 & 13 \\
\hline 47 & 3647 & 12607 & 5 & 6 & 4 & -9 & 2 & 8 & 1 & 15 \\
\hline 48 & 3755 & 12502 & -5 & 10 & 2 & -3 & 5 & 11 & -2 & -6 \\
\hline 49 & 3811 & 12447 & 4 & 8 & 2 & -5 & 4 & 7 & -2 & -8 \\
\hline 50 & 3925 & 12507 & 11 & 1 & 6 & -7 & 5 & 6 & 1 & -4 \\
\hline \multicolumn{3}{|c|}{ Average differences } & 3.95 & 6.88 & 2.96 & 6.96 & 2.5 & 5.96 & 1.78 & 6.16 \\
\hline
\end{tabular}

Data were obtained from 50 tide gauges shown in figure $1 ; \Delta H=$ calculated amplitude - observed amplitude; $\Delta g=$ calculated phase lag - observed phase lag. 
Table III. Comparison between the observed and calculated M2, S2, K1 and O1 tidal currents.

\begin{tabular}{|c|c|c|c|c|c|c|c|c|c|c|c|c|c|c|c|c|c|c|c|}
\hline \multirow[b]{3}{*}{$\begin{array}{l}\text { Sta- } \\
\text { tion }\end{array}$} & \multirow[b]{3}{*}{ Latitude } & \multirow[b]{3}{*}{ Longitude } & \multirow[b]{3}{*}{ Depth } & \multicolumn{4}{|l|}{ M2 } & \multicolumn{4}{|l|}{$\mathrm{S} 2$} & \multicolumn{4}{|l|}{$\mathrm{K} 1$} & \multicolumn{4}{|l|}{$\mathrm{O} 1$} \\
\hline & & & & \multicolumn{2}{|l|}{$\mathrm{U}$} & \multicolumn{2}{|l|}{ V } & \multicolumn{2}{|l|}{$\mathrm{U}$} & \multicolumn{2}{|l|}{$\mathrm{V}$} & \multicolumn{2}{|l|}{$\mathrm{U}$} & \multicolumn{2}{|l|}{$\mathrm{V}$} & \multicolumn{2}{|l|}{$\mathrm{U}$} & \multicolumn{2}{|l|}{$\mathrm{V}$} \\
\hline & & & & $\begin{array}{l}\Delta H \\
\left(\mathrm{~cm} \mathrm{~s}^{-1}\right)\end{array}$ & $\begin{array}{l}\Delta \delta \\
\left(^{\circ}\right)\end{array}$ & $\begin{array}{l}\Delta H \\
\left(\mathrm{~cm} \mathrm{~s}^{-1}\right)\end{array}$ & $\begin{array}{l}\Delta \delta \\
\left(^{\circ}\right)\end{array}$ & $\begin{array}{l}\Delta H \\
\left(\mathrm{~cm} \mathrm{~s}^{-1}\right)\end{array}$ & $\begin{array}{l}\Delta \delta \\
\left({ }^{\circ}\right)\end{array}$ & $\begin{array}{l}\Delta H \\
\left(\mathrm{~cm} \mathrm{~s}^{-1}\right)\end{array}$ & $\begin{array}{l}\Delta \delta \\
\left({ }^{\circ}\right)\end{array}$ & $\begin{array}{l}\Delta H \\
\left(\mathrm{~cm} \mathrm{~s}^{-1}\right)\end{array}$ & $\begin{array}{l}\Delta \delta \\
\left({ }^{\circ}\right)\end{array}$ & $\begin{array}{l}\Delta H \\
\left(\mathrm{~cm} \mathrm{~s}^{-1}\right)\end{array}$ & $\begin{array}{l}\Delta \delta \\
\left(^{\circ}\right)\end{array}$ & $\begin{array}{l}\Delta H \\
\left(\mathrm{~cm} \mathrm{~s}^{-1}\right)\end{array}$ & $\begin{array}{l}\Delta \delta \\
\left({ }^{\circ}\right)\end{array}$ & $\begin{array}{l}\Delta H \\
\left(\mathrm{~cm} \mathrm{~s}^{-1}\right)\end{array}$ & $\begin{array}{l}\Delta \delta \\
\left(^{\circ}\right)\end{array}$ \\
\hline \multirow[t]{2}{*}{ M2 } & 31.39 & 122.37 & 4 & 4.2 & -32 & 11.1 & 121 & 6.5 & 6 & -4.7 & -19 & 0.1 & 55 & 0.2 & 14 & 5.1 & 27 & -1.9 & -16 \\
\hline & & & 13 & 20.5 & 6 & 2.1 & 21 & 3.7 & 6 & -1.1 & 20 & 2.6 & 27 & 1.9 & 42 & 1.6 & 18 & 3.2 & -37 \\
\hline \multirow[t]{3}{*}{ M5 } & 32.01 & 124.5 & 5 & 0.6 & 79 & 2.1 & 62 & -0.5 & -101 & -2.9 & 59 & -20.1 & 7 & -19.4 & 3 & -19.1 & 12 & -15.7 & 9 \\
\hline & & & 20 & 7.3 & -8 & 5.2 & 9 & 4.2 & -25 & 3.2 & -18 & 3.5 & 60 & 2.6 & -62 & 0.9 & -53 & 0.1 & 48 \\
\hline & & & 35 & 11 & -40 & 10.5 & 40 & 4.1 & -40 & 3.1 & -41 & 5 & 16 & 5.5 & -75 & 1.2 & -80 & 3 & 61 \\
\hline \multirow[t]{3}{*}{ M7 } & 30.33 & 123.44 & 5 & -15.1 & -29 & -5.3 & 34 & -4.1 & -4 & 3 & 31 & -18.9 & -8 & -14 & 84 & -13.2 & 6 & -4.8 & 65 \\
\hline & & & 50 & 0.8 & 5 & 3.7 & 9 & 1.6 & -10 & 3.6 & 7 & 1.1 & 25 & -1.7 & 36 & 0.8 & 160 & 0 & -40 \\
\hline & & & 60 & 5 & -36 & 9.1 & 32 & 1.5 & -35 & 5.1 & 35 & 0.7 & 30 & 0.5 & 38 & 0.6 & 120 & 0.6 & -50 \\
\hline \multirow[t]{3}{*}{ MS } & 30.52 & 124.8 & 23 & 1.9 & -18 & -3 & 24 & 4.9 & -5 & 4.5 & 12 & -1.8 & 10 & -3.6 & 3 & -1.8 & -50 & -2.2 & -22 \\
\hline & & & 32 & 4.7 & 5 & 4 & 1 & 4.7 & 20 & 5.1 & 7 & 0.8 & 31 & 0.1 & 4 & -0.1 & 42 & -0.2 & -32 \\
\hline & & & 45 & 7 & -6 & 6 & 9 & 5.1 & 12 & 5.5 & 0 & 1.2 & 18 & 0.2 & 42 & 0 & 41 & -0.3 & 35 \\
\hline CM7 & 28.65 & 125.45 & 20 & -2.1 & 18 & -1.3 & 12 & -3.3 & 28 & -0.3 & 31 & -1.5 & 50 & -1.2 & -11 & 0.3 & 2 & 1 & 60 \\
\hline SB & 28.91 & 127.25 & 177 & -10.7 & -40 & -12 & 32 & -2.1 & -13 & -2.5 & 5 & 2.1 & 41 & -1.5 & -60 & -2.1 & 3 & 0.1 & 8 \\
\hline \multirow[t]{2}{*}{ B } & 36.95 & 124.08 & 38 & 0.5 & -18 & 4.9 & -23 & -0.5 & -30 & 0.1 & -29 & 0.3 & 3 & 2.6 & 12 & 0.3 & 7 & 0.6 & 1 \\
\hline & & & 74 & 6.1 & -15 & 11.5 & -13 & 2 & -29 & 3.4 & -20 & 0.9 & 6 & 5 & 12 & 0.4 & 0 & 2.5 & -6 \\
\hline \multirow[t]{2}{*}{ D } & 36 & 124.58 & 41 & -1.2 & 31 & 31.1 & -20 & -2 & 34 & -0.4 & 33 & 0 & 9 & 2.1 & -13 & 0.1 & 63 & 0.3 & 3 \\
\hline & & & 86 & -1.4 & 30 & 10.1 & -17 & -1.9 & 29 & 4.1 & 30 & -0.5 & 61 & 5.4 & -18 & -0.2 & 47 & 2.5 & -9 \\
\hline \multirow[t]{2}{*}{$\mathrm{F}$} & 35.23 & 124.74 & 70 & -3.5 & 27 & 1 & -17 & 0.7 & 50 & -2 & -40 & -0.8 & 1 & 1.5 & -16 & -1.2 & 26 & -0.1 & -4 \\
\hline & & & 94 & 0.1 & 9 & 11.5 & 12 & 0.9 & 18 & 4.5 & -10 & -0.5 & 21 & 5.1 & -15 & -0.5 & 29 & 2.2 & 17 \\
\hline I & 34.3 & 124.96 & 48 & 2 & 3 & 3 & -20 & -0.5 & 9 & 0.6 & -30 & -0.8 & 30 & -0.4 & -23 & 0 & 18 & -0.3 & 0 \\
\hline $\mathrm{C}$ & 36.95 & 125.41 & 52 & 17.1 & 17 & -15 & -28 & -6 & 25 & 5 & -36 & 1.5 & 4 & 4.1 & -18 & 0.5 & 11 & 2 & 1 \\
\hline $\mathrm{E}$ & 36.03 & 125.6 & 63 & 11.8 & 16 & 12 & 38 & 3.5 & 24 & 3 & -24 & 1.2 & 1 & 4 & -6 & -0.5 & 16 & 2.4 & 5 \\
\hline \multirow[t]{4}{*}{ M4 } & 31.25 & 122.82 & 2 & 4.1 & -11 & -5.2 & -18 & 4 & 34 & -1 & 23 & -0.8 & 32 & -4.1 & 22 & -2.9 & -16 & -2.5 & 9 \\
\hline & & & 25 & 10.4 & 2 & -2.4 & -10 & 4.5 & 7 & -0.4 & 1 & -3.2 & 6 & -2.6 & -18 & -2.9 & 26 & 0.3 & -16 \\
\hline & & & 38 & 14.1 & 10 & 5.6 & 1 & 8.1 & 12 & 3.2 & 9 & -4.5 & 9 & -0.7 & -2 & -3.5 & 23 & 1.5 & 12 \\
\hline & & & & 6.53 & 20.4 & 7.55 & 24.9 & 3.24 & 24.2 & 2.89 & 22.8 & 2.98 & 22.4 & 3.6 & 25.9 & 2.39 & 35.8 & 2.01 & 22.6 \\
\hline
\end{tabular}

Data were obtained from 13 mooring stations shown in figure $1 ; \Delta H=$ calculated amplitude - observed amplitude in $\mathrm{cm} / \mathrm{s} ; \Delta \delta=$ calculated phase lag - observed phase lag in degree;

$\mathrm{U}=\mathrm{u}$-component of tidal current; $\mathrm{V}=\mathrm{v}$-component of tidal current. 

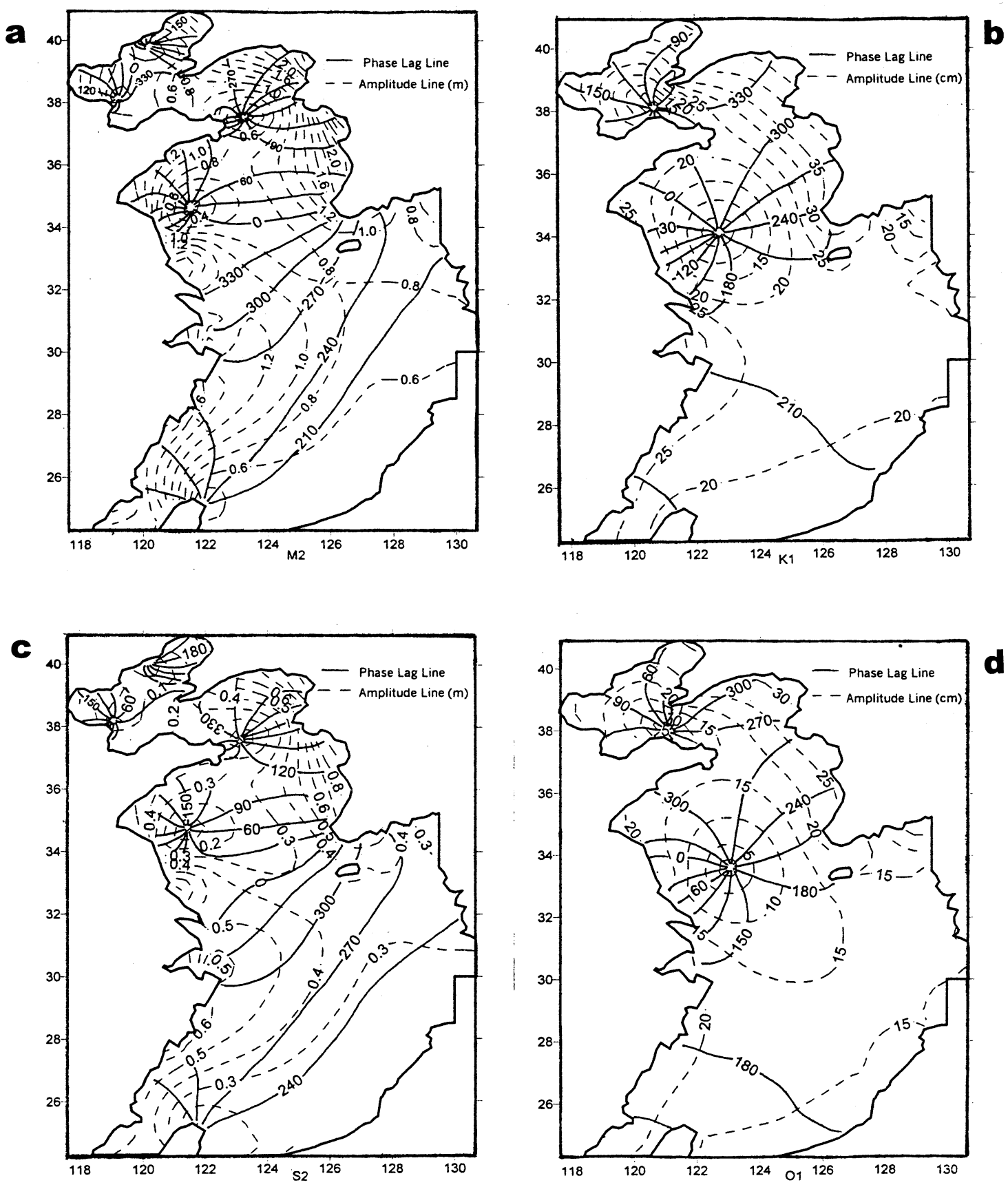

Figure 2. Distribution of co-amplitude and co-phase lag lines of M2 (a), K1 (b), S2 (c), and O1 (d) constituents.

are both to the north of those found in this study, because the phase lag on the open boundary in Guo's model is larger than that in this study. There exists a degenerative tidal wave system at the northern Taiwan Island. In each tidal wave system, a zone of the maximum elevation amplitude is in the offshore region, which is the farthest to its amphidromic point. For example, the maximum amplitudes of the M2 and S2 elevations are found at Inchon and Asan on the coast of Korea in the northern Yellow Sea wave system and at Tanggu (station 10), and 

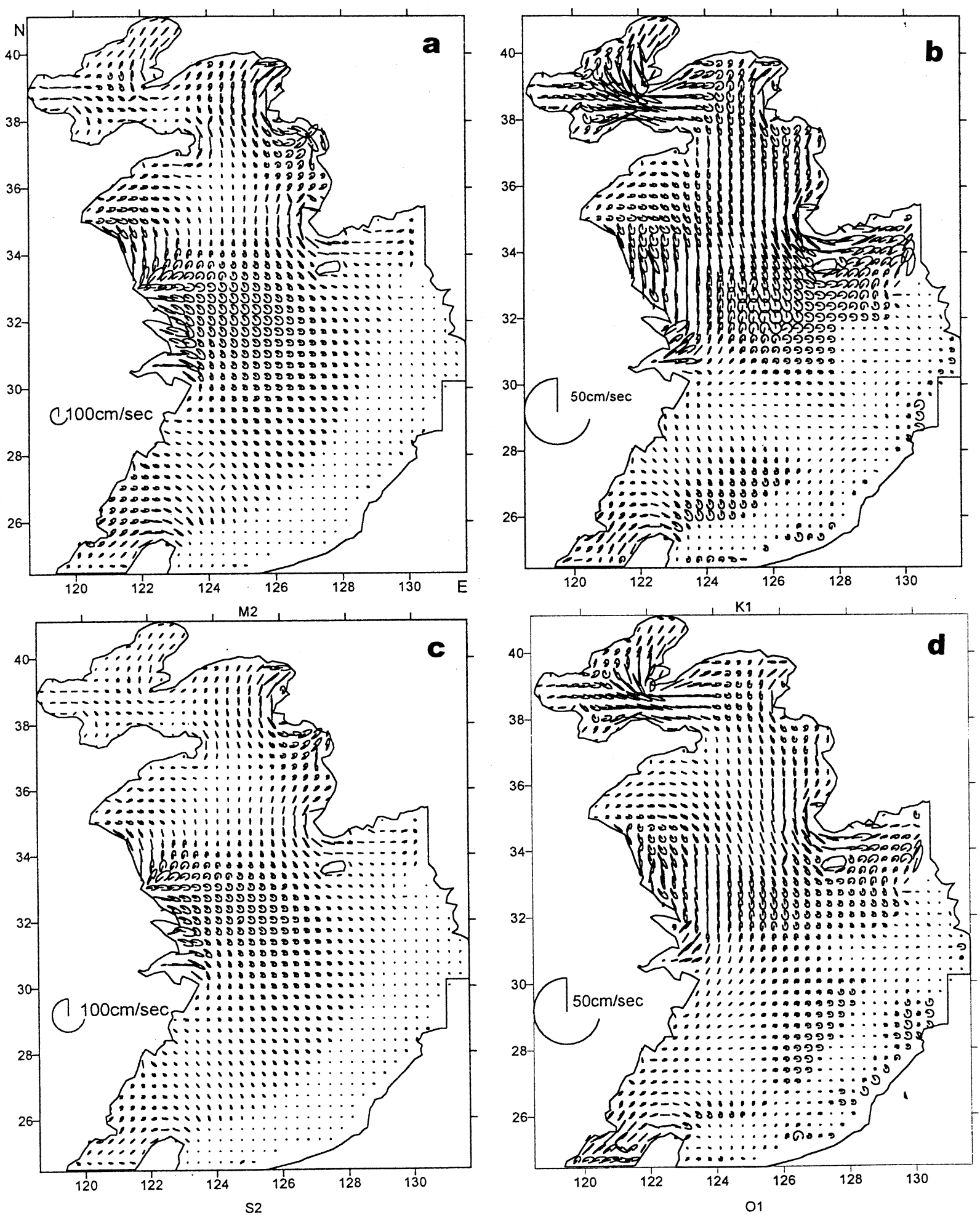

Figure 3. Horizontal distributions of M2 (a), K1 (b), S2 (c), and O1 (d) tidal current ellipses on the sea surface. 
Yingkou (station 5) in the Bohai Sea. Due to the effect of topography in modifying tides, the contours of the harmonic (such as a contour of $1.2 \mathrm{~m}$ ) show a tongue shape in the area off the mouth of Changjiang River and the Hangzhou Bay. The distributions of harmonic amplitudes are different from the results of Wan et al. (1998) and Wang et al. (1999), but similar to the results of Fang (1986) and Ye and Mei (1995).

The pattern of the $\mathrm{K} 1$ wave system is similar to the $\mathrm{O} 1$ wave system. The diurnal tide waves are controlled by two systems. An amphidromic is located in the Bohai Strait and the other in the southern Yellow Sea. Comparison of M2 with S2 tide system, the diurnal tides are more stable than semi-diurnal tides in the EYS. Reproduction of the amphidromic points of diurnal tides is not as sensitive as semi-diurnal tides to bed drag coefficient in the model. The zone of the maximum amplitude elevation is in the offshore farthest from its amphidromic point. For example, the maximum amplitudes of the $\mathrm{K} 1$ and $\mathrm{O} 1$ elevations are found at Unmu Island on the coast of Korea in the northern Yellow Sea wave system, and at Tanggu (station 10) and Yingkou (station 5) in the Bohai Sea.

The co-tidal chart reproduced by the model clearly shows that the tidal waves come from the Pacific Ocean through straits around the Ryukyu Islands. The increase in tidal amplitude and current from ocean to shelf and within the East China Sea is clearly evident. The tidal wave in the East China Sea is propagated wave. Due to wave reflection from the coastal line in the Yellow Sea, semi-diurnal tidal waves are changed into location waves, which have two amphidromic points, and diurnal tidal waves are changed into located waves, which have one amphidromic point. When transmitted into the Bohai Sea through the Bohai Strait, the tide systems that have two amphidromic points are located at the Yellow River mouth and Qinhuangdao for semi-diurnal tide, and tide systems with one amphidromic point at the Bohai Strait for diurnal tide, are produced in the Bohai Sea.

\subsection{Tidal current characteristic}

Figure 4 shows the calculated M2, S2, K1 and O1tidal ellipses at the surface in the EYS. The ellipse charts give the magnitudes and rotary directions of the tidal currents by representing maximum and minimum velocities as major and minor axes respectively. The direction of rotation is indicated from bar to the circle end. The pattern of semi-diurnal tidal ellipse is similar in EYS, but the value of the M2 tidal current is larger than that of S2. The major and minor axes of the Changjiang River mouth are nearly the same, therefore the tidal mixing there is always strong. On the continental shelf (depth less than $200 \mathrm{~m}$ ) however, the major axis is clearly longer than the minor axis, which means that the tidal mixing across the depth contour is stronger than that along it. Figure 4 shows clearly three rectilinear regions that are located in the middle of the Yellow Sea, the Bohai Strait and the Liaodong Bay. The three regions have been verified by observation current data. Five rotation current systems are also shown in figure 4. The currents in northwest of the Taiwan Island, southeast to the Shangdong Peninsula and the Korea coast, rotate in an anti-clockwise direction, while those in the Changjiang River mouth and the middle Bohai Sea are in a clockwise direction.

The distribution of the $\mathrm{K} 1$ tidal current is similar to those of O1 in EYS. Figure 4 shows clearly three rotary current regions, which are located at the southern of the Yellow Sea, southeast to the Shangdong peninsula, and on the Korea coast, respectively. One current in the southern Yellow Sea rotates clockwise, while the others rotate anti-clockwise. A difference of diurnal tidal current shows that the $\mathrm{O} 1$ tidal current rotates in the middle of the East China Sea, while that of K1 does in northeast to the Taiwan Island.

Generally speaking, tidal currents over the shelf from the continental edge to the entrance of the Yellow Sea rotate in a clockwise direction, while the currents in the Yellow Sea are rectilinear following their direction of propagation along the coast.

The distributions of maximum currents of M2, S2, K1 and $\mathrm{O} 1$ tide in the EYS are shown in figure 5. The strong diurnal currents are located in the Bohai Strait, the Jeju Strait, Sechan Bay and the mouth of Changjiang River. The strongest current is on order of $50 \mathrm{~cm} \mathrm{~s}^{-1}$ in the Bohai Strait. The semi-diurnal currents are high on the west coast of Korea and the entrance to the Changjiang River, and are on the order of $100 \mathrm{~cm} \mathrm{~s}^{-1}$, which is indicative of a strong dissipation. These results are in good agreement with Fang (1986) and Lefevre et al. (2000). The velocity in the Strait in our model is not as strong as reported by Choi $(1984,1989)$. The semi- 

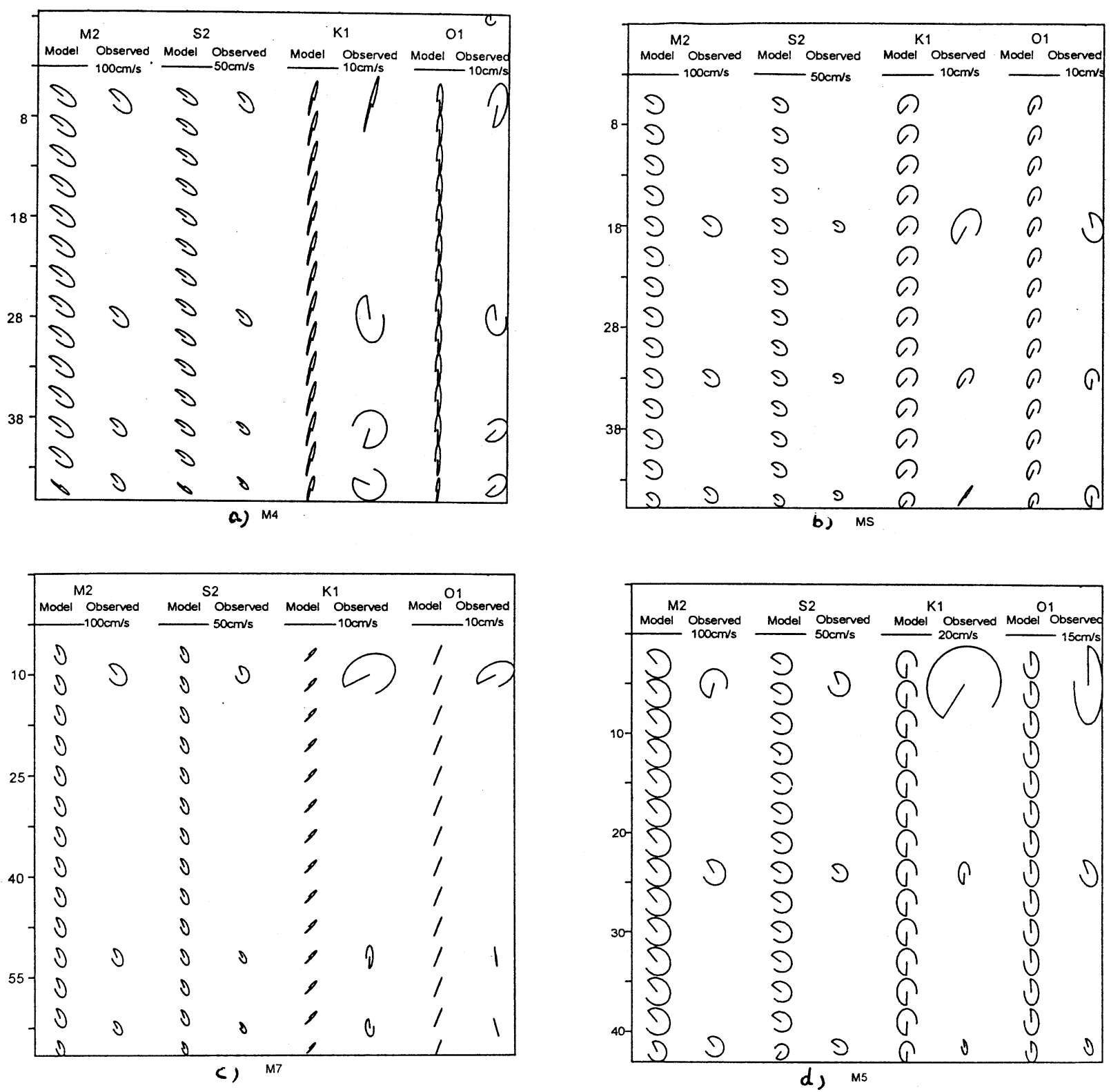

Figure 4. Comparison of M2, S2, K1 and O1 model current ellipses with currents observed at stations M4 (a), MS (b), M7 (c), and M5 (d). The line within each ellipse is the major semi-axis; the rotation direction is from lined end to circle end.

diurnal tidal currents, which are two main tidal currents in the EYS, would affect some physical processes in the region. Two weak semi-diurnal current regions located in the middle and northern Yellow Sea coincide with two centers of the Yellow Sea Cold Water Mass (Guan, 1963). A strong current tongue spreading to the southeast offshore from the mouth of the Changjiang River is shown in figure 5. The water mixing caused by tidal currents would affect the mechanism of diluting Changjiang waters. This pattern of semi-diurnal tidal current distribution explains well the distribution of sediment in the EYS (Yoshiki and Yang, 1993), because the areas of clay are located in the small current regions and the areas of sand are located well in the large current regions. 

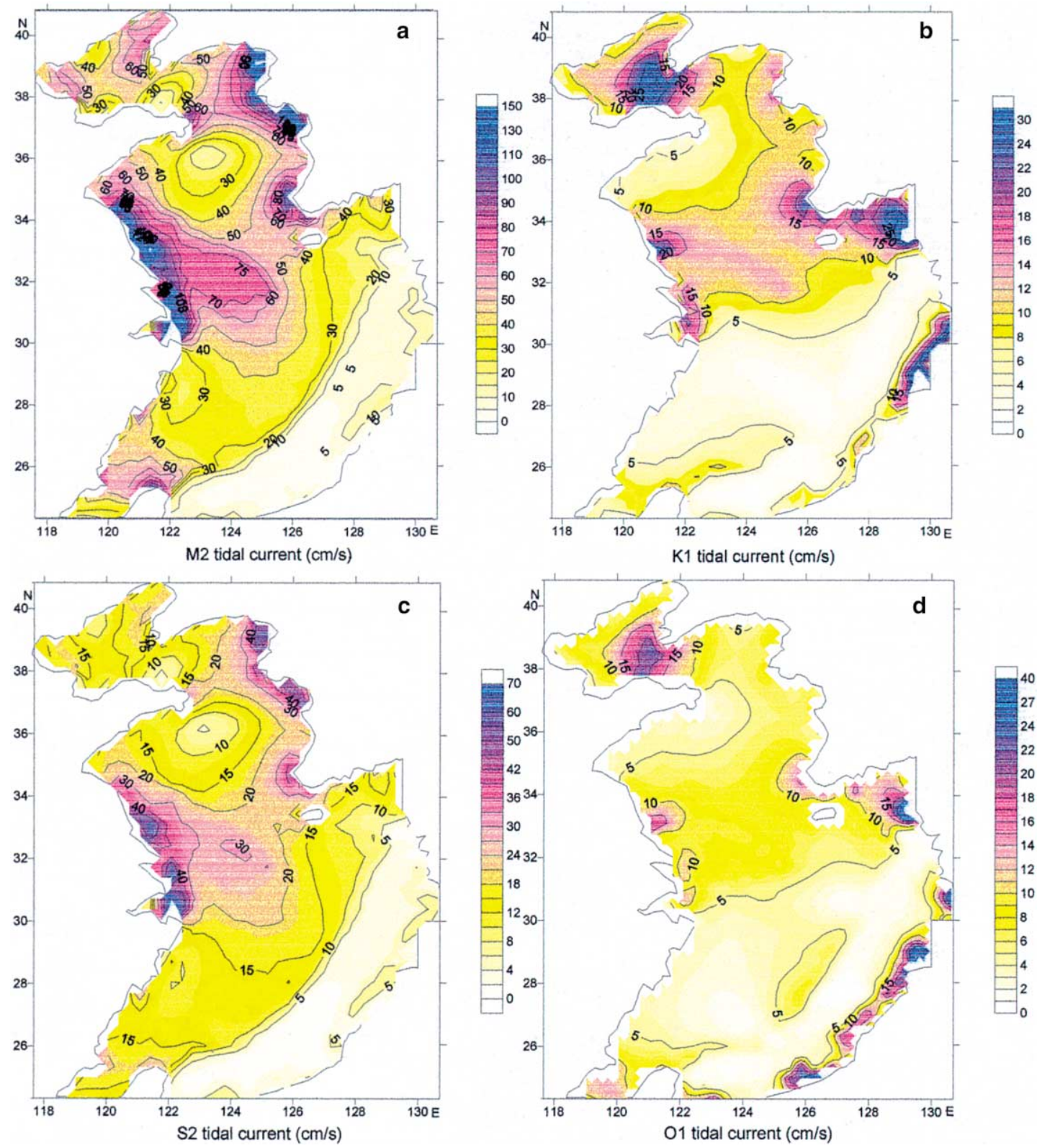

Figure 5. Distribution of maximum currents of M2 (a), K1 (b), S2 (c), and O1 (d) tides in the East China Sea.

\section{CONCLUSION}

A three-dimensional tidal model, including a closure turbulence sub-model, was built and applied to simulate the M2, S2, K1 and O1 tides in the EYS. The modelgenerated amplitudes and phase-lags of tide elevations and currents are in good agreement with observations, which indicates that the model is quite successfully used to simulate the tide and tidal currents in the EYS. Some results of the tidal model in the EYS are as follows:

- The bottom friction is an important factor that affects the tide charts in the EYS. In the quadratic friction form, the bed drag coefficient should be non-uniform and in a depth-dependent form in the EYS tide model. The value of bed drag coefficient is about 0.0015 . 
- There exist two and four amphidromic points in diurnal and semi-diurnal tide system in the EYS. Maximum amplitudes of M2 and S2 elevations are found at Inchon and Asan on Korea coast and those for the K1, O1 at Unmu Island. The patterns of M2 and K1 are similar to those for the S2 and O1 respectively. The velocity of semi-diurnal currents is high on the western coast of Korea and at the entrance to the Changjiang River, and is in the order of $100 \mathrm{~cm} \mathrm{~s}^{-1}$. Strong diurnal currents are found in the Bohai Strait, the Jeyu Strait and at the mouth of Changjiang River. The tidal currents over the shelf from the continental edge to the entrance of the Yellow Sea are rotating clockwise, while the currents in the Yellow Sea are rectilinear following their direction of propagation along the coast.

- Some important phenomena such as the Yellow Sea Cold Water Mass, sediment process and the Changjiang diluted water are related to the distribution of tidal currents. Studies of these processes mechanisms should consider the distribution of tidal current in EYS.

\section{Acknowledgements}

We should like to emphasize the contribution of Professors Sun Wenxing, Huang Zuke, and Ph.D. Wang Kai to this work, and we also thank Professor Shi Maochong for helpful discussions of the results. I wish to express my sincere appreciation to Professor John Morrison for critically reading the article and offering advices. This work was supported by the Chinese Education Ministry Program (00080), 863 Natural Program (818-Q-12), and NSFC (40076001).

\section{REFERENCES}

An, H.S., 1977. A numerical experiment of the M2 tide in the Yellow Sea. J. Oceanogr. Soc. Japan 33, 103-110.

Bao, X., Yan, J., Sun, W., 2000. A three-dimensional tidal model in boundary-fitted curvilinear grids. J. Estuarine Coast Shelf Sci. 50, 775-788.

Blumberg, A.F., Mellor, G.L., 1987. Three-dimensional coastal ocean models. Coastal Estuarine Sci. 4, 1-16.

Casulli, V., 1990. Semi-implicit finite difference methods for the two-dimensional shallow water equations. J. Comput. Phys. 86, 56-74.

Choi, B.H., 1984. A three-dimensional model of the East China Sea. In: Ichiye, T. (Ed.), Ocean hydrodynamics of the Japan and East China Seas. Elsevier, Amsterdam, pp. 167-185.
Choi, B.H., 1989. A fine-grid three-dimensional M2 tidal model of the East China Sea. In: Davies, A.M. (Ed.), Modeling marine systems. CRC Press, Inc., Boca Raton, FL, pp. 167-185.

Davies, A.M., Kwong, S.S.C., Flather, R.A., 1997. Formulation of a variable-function three-dimensional model, with application to the M2 and M4 tide on the northwest European continental shelf. Cont. Shelf Res. 17, 165-204.

Ding, W., 1984. A study on the characteristics of the tide and tidal current the East China Sea. Stud. Mar. Sin. 21, 135-148.

Fang, G., 1986. Tide and tidal current charts for the marginal seas adjacent to China. Chin. J. Oceanol. Limnol. 4, 1-16.

Guan, B.X., 1963. The temperature variation and current structure in the Yellow Sea Cold Water Mass.. Oceanol. Limnol. Sin. 5, 255-284.

Guo, X., Yanagi, T., 1998. Three-dimensional structure of tidal current in the East China Sea and the Yellow Sea. J. Oceanogr. 54, 651-668.

Kang, S.T., Lee, S., Lie, H., 1998. Fine grid tidal modeling of the Yellow and East China Seas. Cont. Shelf Res. 18, 739-772.

Larsen, L.H., Cannon, G.A., Choi, B.H., 1985. East China Sea tide currents. Cont. Shelf Res. 4, 77-103.

Lee, J.C., Jung, K.T., 1999. Application of eddy viscosity closure models for the M2 tide and tidal currents in the Yellow Sea and the East China Sea. Cont. Shelf Res. 19, 445-475.

Lefevre, F., Le Provost, C., Lyard, F.H., 2000. How can we improve a global ocean tide model at a regional scale? A test on the Yellow Sea and the East China Sea. J. Geophys. Res. 105, 8707-8725.

Mellor, G.L., Yamada, T., 1982. Development of a turbulence closure model for geophysical fluid problems. Rev. Geophys. Space Phys. 20, 851-857.

Nishida, H., 1980. Improved tidal charts for the western part of the North Pacific Ocean. Rep. Hydrogr. Res. 15, 55-70.

Ogura, S., 1933. The tides in the sea adjacent to Japan. Bulletin of the Hydrographic Department, Imperial Japanese Navy 7, 1-189.

Shen, Y., 1980. Numerical computation of tides in the East China Sea. J. Shandong Coll. Oceanol. 10, 26-35.

Wan, Z., Qiao, F., Yuan, Y., 1998. Three dimensional numerical modeling of tidal waves in the Bohai, Yellow Sea and East China Sea. Oceanol.. Limnol. Sin. 29, 611-616.

Wang, K., Fang, G., Feng, S., 1999. A 3D numerical simulation of M2 tidal and tidal currents in the Bohai Sea, Yellow Sea and the East China Sea. Acta Oceanol. Sin. 21, 1-13.

Yanagi, T., Inoue, K., 1994. Tide and tidal current in the Yellow/East China. Seas. Lamer 32, 153-165.

Yoshiki, S., Yang, Z., 1993. Sediment budget in the East China Sea, Third symposium on geo-environments and geotechnics.. Terra Scientific Publications, Tokyo, pp. 123-128.

Ye, A., Mei, L., 1995. Numerical modeling of tidal waves in the Bohai Sea, the Huanghai Sea and the East China Sea. Oceanol. Limnol. Sin. 26, 63-70

Zhao, B., Fang, G., Chao, D., 1994. Numerical simulations of the tide and tidal current in the Bohai Sea. Acta Oceanol. Sin. 16, 1-10. 